Research Article

\title{
'Mental Health Study': The Rural Population Fares Better than the Medical Staffs \& Students of the Area; A Cross Sectional Analysis
}

\author{
Badri Narayan Mishra', Mudit Kumar Gupta² \\ ${ }^{1}$ Professor, Community Medicine, Ruxmaniben Deepchand Gardi Medical College, Ujjain, Madhya Pradesh, India. \\ ${ }^{2}$ Ex. Intern. PIMS, Loni, Maharashtra, India.
}

DOI: https://doi.org/10.24321/2394.6539.202001

\section{I $\quad \mathbf{N} \quad \mathbf{F} \quad \mathbf{O}$}

\section{Corresponding Author:}

Badri Narayan Mishra, Community Medicine, Ruxmaniben Deepchand Gardi Medical College, Ujjain, Madhya Pradesh, India.

E-mail Id:

badrinmishra@gmail.com

Orcid Id:

https://orcid.org/0000-0001-6956-0469

How to cite this article:

Mishra BN, Gupta MK. 'Mental Health Study': The Rural Population Fares Better than the Medical Staffs \& Students of the Area; A Cross Sectional Analysis. J Adv Res Med Sci Tech 2020; 7(1): 4-7.

Date of Submission: 2020-04-13

Date of Acceptance: 2020-05-02

\section{$\begin{array}{llllllll}\mathbf{A} & \mathbf{B} & \mathbf{S} & \mathbf{T} & \mathbf{R} & \mathbf{A} & \mathbf{C} & \mathbf{T}\end{array}$}

Mental health is a perennially neglected domain; more so, it is a comparative evaluation across different accessible strata.

Aim: The reporting cross-sectional study aimed at enumerating and comparing different stress factors amongst teachers, students, clerical staffs and local residents in a rural medical university and its field practice area.

Result: A total of 400 participants were studied over a period of 3 months belonging to four groups with equal number (50 each). Out of these $221(55.25 \%)$ recorded mild stress and $10(2.5 \%)$ recorded stress scores needing urgent intervention. For the student, new entrants $(<3$ years of residential experience) had higher stress prevalence at $36(72 \%)$ as compared to their seniors at $27(54 \%)$ who had a history of $>3$ year residential experience. For faculty, $38(76 \%)$ recorded moderately high stress score irrespective of their campus residency. For clerical and paramedical staffs, duration of residence was detrimental in stress generation. Moderate and severe stress was apparent in the less than 3 years resident category at $6(12 \%)$ and $1(2 \%)$ as compared to $1(2 \%)$ and $0(0 \%)$ in over 3 year groups. The natives of the rural area experienced lowest stress level, with an average stress score of 169.44, for males and 170.42 for female which was less than the cut off value of 178 .

Conclusion: Rural residency with nativity status and longer duration of stay for working and student class were associated with less mental stress level where as new students and faculties of the health university experienced a higher score. The result points at initiating intervention strategy at work place for stress management.

Keywords: Mental Stress, Medical University Residents, Duration of Stay, Local Populace 


\section{Introduction}

Out of the four major components of health i.e. physical, social, mental and spiritual, the last two have faced isolation over last couple of centuries., ${ }^{1,2}$ National Mental Health Survey of India 2015-2016 found out that, "Every sixth Indian needs mental health help;" whereas WHO (World Health Organization) in its recent report puts this figure at $7.5 \%{ }^{3,4}$ As per a latest study reported in Lancet Psychiatry (2020), in 2017 India had 197.3 million (95\% UI 178.4-216.4) people with mental disorders, which includes, $45 \cdot 7$ million (42.4-49.8) with depressive disorders and 44.9 million (41.2-48.9) with anxiety disorders. ${ }^{5}$ Furthermore, as per a 1917 data, mental disorders were the second leading cause of disease burden in terms of Years Lived with Disability (YLDs) and the sixth leading cause of Disability-Adjusted Life-Years (DALYS) in the world in 2017, posing a serious challenge to health systems, particularly in low-income and middle-income countries. ${ }^{6}$ Stress is the condition that results when person-environment transactions lead the individual to perceive a discrepancy, whether real or not, between the demands of a situation and the resources of the person's biological, psychological or social systems. In medical terms, stress is the disruption of homeostasis through physical or psychological stimuli. Stressful stimuli can be mental, physiological, anatomical or physical. ${ }^{7}$

In the present study we tried to evaluate different stress factors and the levels of stress experienced among the faculty, staffs, students of a rural Medical university situated in Western Maharashtra, and the permanent residents in its practice area.

\section{Aim}

The study was aimed at assessing the prevalence and compares the causes of mental health stressors in different study groups.

\section{Objectives}

- Assessment of prevalence of anxiety and depression among different study groups.

- To find out their different contributors and associate them with socio-economic, academic, and health factors.
- To suggest measures to improve the situation.

\section{Methodology}

A pilot tested cross sectional study was carried out under the stewardship of ICMR-STS project bearing reference no. - 21/509/08-BMS over a period of 3 months in a medical university in Western Maharashtra and its adjacent villages. 400 consenting participants were randomly selected from the study population. For maintaining equanimity, the participants selected were 100 each from the major groups and each group had equal participants (50 each) for their subgroups. The major groups were students, faculties, staffs and rural residents and their sub groups were duration of residence in campus ( < or > 3 years) for university residents, and males and females for local village residents.

A self-administered questionnaire consisting of 4 components and scored on Likert scale of 1 to 4 (1=never, $2=$ rarely, $3=$ =sometimes, $4=$ often) was administered to access general socio-demographic factors, behavioral components, physical signs and stress prone characters. The mean of the total score demonstrated normal Gaussian distribution was calculated. The standard deviation of $\pm 1, \pm 2$ and \pm 3 were used to grade the severity of mental stress. The range for normal was between mean \pm 1 SD (Standard Deviation), for borderline was between mean $\pm 2 S D$, for moderate was between mean $\pm 3 S D$ and sever was $>3 S D$. Inferential Data analysis was done by $Z$ test, through calculation of standard error (SE), where SE $\left(p_{1}-p_{2}\right)$ and degrees of freedom was 1.

\section{Result}

The participants score ranged from 76 to 304 , with the mean at 177.5. Out of 400 participants 221 (55.25\%) recorded mild stress and $10(2.5 \%)$ recorded stress scores needing urgent intervention.

The break ups of the different grades of stress scores for studied participants are depicted in Table 1.

On subgroup analysis 27 (54\%) of students with more than 3 years of campus residency showed moderate stress level in comparison to 36 (72\%) moderate stress score in < 3year resident students. Whereas in case of faculty with campus residency over 3 years, 38 (76\%) reported moderate stress scores and only 12 (24\%) had a normal scores level.

Table I.Distribution participants with respect to grades of mental stress

\begin{tabular}{|c|c|c|c|}
\hline Stress Range & No. of persons & Percentage & Category \\
\hline$<165$ & 64 & $16 \%$ & Normal \\
\hline $166-178$ & 105 & $26.25 \%$ & Morderline \\
\hline $179-191$ & 221 & $55.25 \%$ & Moderate stress \\
\hline $192-204$ & 8 & $2 \%$ & Severe stress \\
\hline $205-217$ & 2 & $.5 \%$ & \\
\hline Total & 400 & $100 \%$ & \\
\hline
\end{tabular}


The detailed break ups of subgroup analysis for teachers with over 3 years residency is presented in Figure 1.

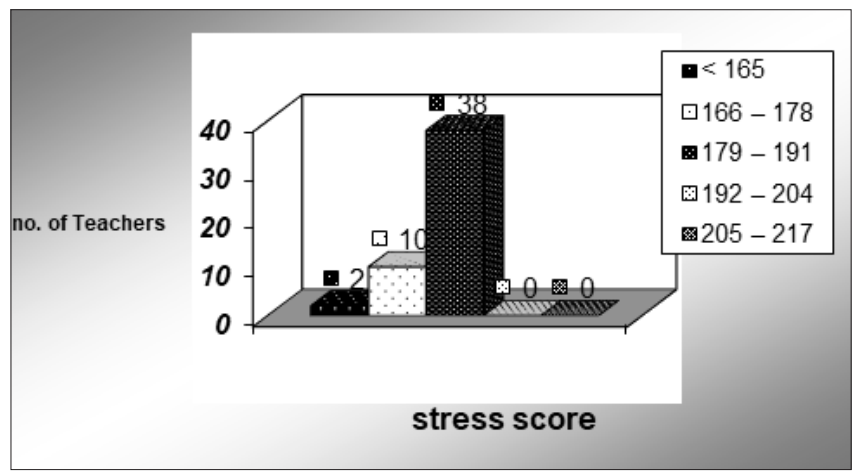

Figure I.Bar diagram showing stress score of Teachers residing over 3 years in campus

Unlike the case with students, there were no differences in stress category for faculty with respect to residency. Both groups showed equal percentages in the different sub grades of mental stress i.e. $2(4 \%)$ were in normal grade, $10(20 \%)$ at borderline and $38(76 \%)$ at mild stress with an average stress score of 182.28 , which is above the cut off value of 178 .

In clerical and paramedical staffs from $>3$ years category, $18(36 \%)$ were normal, 8 (16\%) were at borderline, 24 (48\%) were in mild stress and $1(2 \%)$ in severe stress category and their average stress score was 173.56 (Figure 2). For their counterpart the respective figures were $8(16 \%), 11$ (22\%), $24(48 \%), 6(12 \%)$ and $1(2 \%)$ and average stress score at 179.06 , thereby reflecting a higher prevalence of mental stress in junior clerical and paramedic groups.

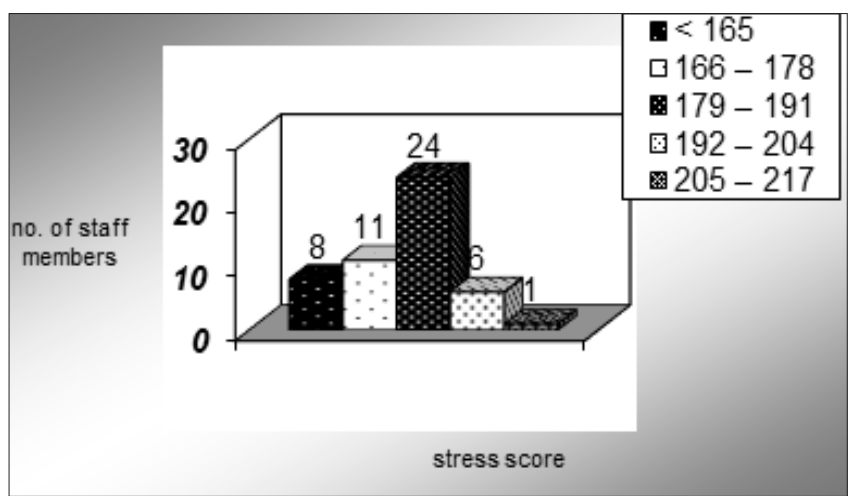

Figure 2.Bar diagram showing stress score of clerical staff with reference to campus residency (Less than 3 yrs)

In the male natives of rural area, 17 (34\%) were in normal range, 15 (30\%) were at borderline, $17(34 \%)$ in mild stress and $1(2 \%)$ in moderate stress, with an average stress score of 169.44. and for females the corresponding figures were, $13(26 \%)$ normal range, $19(38 \%)$ at borderline, $17(34 \%)$ in mild stress and $1(2 \%)$ in moderate stress, with an average stress score of 170.42 .

\section{Discussion}

A Z-test value of 4.2899 at $1 \%$ level of significance i.e. $p$ $<0.01$ suggests that students were at greater stress and may be more prone to stress related diseases than the natives of Rural area. Similar observation were made by other researchers. ${ }^{8-12}$

Highly significant difference between stress levels of teachers (doctors) and rural natives were apparent from the Z-value at $6.583(p<0.01)$. Similar observations were documented by other studies where doctors were as one of the most stressed groups. ${ }^{13-17}$

On comparison of mild (grade 2) stress scores of teachers and students the Z- value was at $2.0155(p<0.05)$; implying thereby the existence of a significant difference between stress levels of teachers and students; hence putting them at increased risk of mental stress and its associated conditions.

High level of stress among teachers of both the study group was reported. Inter group evaluation showed no significant variation. Studies indicating doctors and teaching professionals as high stressed groups are aplenty. ${ }^{18-22}$

High levels of severe and very severe stress in recently employed (<3 yrs) paramedics and clerics of the institute may be due to change of place, new working environment and difficulty in cultural and work adjustments. Similar observations were recorded by other researchers, putting recent employment and change of place as stress precipitators. $^{23-25}$

Though the average stress score for both males and females among local natives were below the mean (cut off value=178), the females recorded a slight high average than the males thus putting them at more risk of developing stress and its related disorders. ${ }^{20-22}$

\section{Conclusion}

There is increased level of mental stress in individuals who are away from family for less than 3 years as they are still in a phase of adoption regardless of age and gender and also profession. Depressive symptoms and perceived stress are public health concerns more so among faculty, doctors, students and paramedics. Stress at work is also associated with very high educational level and high occupational position. Common stressors documented were change of place,work environment, difficult people, daily hassles, medical illness and discrimination.

Employers should take note of these findings and draft policies encorporating better work culture, scopes for recretions, enhanacment of interpersonal relationship. Employees, and seniors should also take initiatives in creating work place conducive for new entrants. A mentally healthy work force and student commune can bring stability to the institute and help built its reputaion. 


\section{Aknowledgement}

We are thankful to Dr. SK Shukla for his assistance in data analysis. And participants for their support.

Ethical Clearance: ICMR-STS project bearing reference no. - 21/509/08-BMS.

\section{Source of Support: ICMR \\ Conflict of Intrest: None \\ References}

1. WHO, world health report, mental health: new understanding new hope. Report of the Director General WHO 2001. 134-137.

2. Rippetoe-Kilgore, Mark, Lon. Practical Programming for Strength Training." ISBN 0-9768-0540-5, 2006.

3. The National Mental Health Survey of India, 2015-16, Insights, 31, December. 2016.

4. Neerja Birla, Mental health in India: $7.5 \%$ of country affected. The Economic Times; https://economictimes. indiatimes.com.

5. Dandona $L$. The burden of mental disorders across the states of India: the Global Burden of Disease Study 1990-2017. Lancet Psychiatry 2020; 7: 148-161. https:// doi.org/10.1016/ S2215-0366(19)30475-4.

6. Institute of Health Metrics and Evaluation. GBD compare data visualisation. https://vizhub.healthdata. org/gbd-compare/ (accessed July 24, 2019).

7. Ron de Kloet et-al. Stress and the brain: from adaptation to disease. Nature Reviews Neuroscience 2005; 6(6): 463-475.

8. Pelletier K, Herzing D. Psychoneuroimmunology: toward a mind and body model - critical review. Advances $J$ Inst Adv Health 1988: 5: 27-56.

9. Goetzel RZ et-al. Health Enhancement Research Organization (HERO) Research Committee. The Relationship between modifiable health risks and health care expenditures: an analysis of the multiemployer HERO health risk and cost database. J Occup Environ Med 1988; 40: 843-854.

10. Shapiro S, Shapiro DE, Shwartz GER. Stress management in medical education. Acad Med 2000; 75: 748-759.

11. Deckard G, Meterko M, Field D. Physician burnout: an examination of personal, professional and organizational relationships. Med Care 1994; 32: 745-754.

12. Cohen S, Janicki-Deverts D, Miller GE. Psychological stress and disease. JAMA 2007; 298(14): 1685-1687.

13. Melamed S, Shirom A, Toker S, Shapira I. Burnout and risk of type 2 diabetes: a prospective study of apparently healthy employed persons. Psychosom Med 2006; 68(6): 863-869.

14. Miller T. Stressful life events" Madison, Wis: International Universities Press; 1989, Stress and Health Series. Monograph 4-12.
15. St Paul Fire, Marine Insurance Co. American Workers under Pressure. St paul, Minn: St Paul Fire and Marine Insurance Co.; 1992. Technical report. 123-132.

16. Selye, Hans. Diseases of adaptation. Wisconsin medical journal 1950; 49(6): 87-89.

17. Seyle, Hans. A syndrome produced by diverse nocuous agents. Nature 1956; 58: 16-18.

18. US Dept. of health and human Services. Healthy people 2010. $2^{\text {nd }} \mathrm{ed}$. With understanding and improving health. 2000; 1(2): 187-192.

19. Wege N et-al. When does work stress hurt? Testing the interaction with socioeconomic positioning the Heinz Nixdorf Recall Study. IJPSM 1989; 23(3\&4): 23-27.

20. Hamad R et-al. Social and economic correlates of depressive symptoms and perceived stress in south African adults. JSACP 2001; 23(1); 43-48.

21. Michael G et-al. Stresses of Daily Life. AJCE 2007; 35(1): 26-29.

22. Wang JL et-al. The relationship between work stress and mental disorders in men and women: findings from a population based study. IJMS 38(4): 76-79.

23. Nguyen CTMH, Goldberg JH, sheikh Jl. The management of stress and anxiety in Medical Disorders. The geriatric patient. In Motofsky DI, Barlow DH, edition. 2, chapter3; 32-33. 2000.

24. Foley DJ et-al. Sleep complaints among elderly persons: An Epidemiologic Studies of three communities. Sleep 1995; 32(2): 12-15.

25. Sapolsky RM. Why Zebras don't get ulcers. New York, NY: Freeman; 1994. 